\title{
A Non-Interventional, Cross-Sectional Study to Evaluate Factors Relating to Daily Step Counts and Physical Activity in Japanese Patients with Chronic Obstructive Pulmonary Disease: STEP COPD
}

This article was published in the following Dove Press journal:

International Journal of Chronic Obstructive Pulmonary Disease

\author{
Masakazu Ichinose' \\ Yoshiaki Minakata $\mathbb{D}^{2}$ \\ Takashi Motegi ${ }^{3}$ \\ Tsuneyuki Takahashi ${ }^{4}$ \\ Munehiro Seki $\mathbb{D D}^{5}$ \\ Satoko Sugaya ${ }^{5}$ \\ Nobuya Hayashi (iD ${ }^{6}$ \\ Ichiro Kuwahira ${ }^{7}$ \\ 'Academic Center of Osaki Citizen \\ Hospital, Osaki 989-6183, Japan; \\ ${ }^{2}$ Respiratory Medicine, National Hospital \\ Organization Wakayama Hospital, \\ Wakayama 644-0044, Japan; ${ }^{3}$ Respiratory \\ Care Clinic Tokyo, Institute of Clinical \\ Respirology, Tokyo 104-003I, Japan; \\ ${ }^{4}$ Department of Internal Medicine, \\ Tohoku Medical and Pharmaceutical \\ University Wakabayashi Hospital, Sendai \\ 984-8560, Japan; ${ }^{5}$ Medical Department, \\ AstraZeneca K.K., Osaka 530-00II, \\ Japan; ${ }^{6}$ Biometrics Department, \\ AstraZeneca K.K., Osaka 530-00II, \\ Japan; ${ }^{7}$ Department of Pulmonary \\ Medicine, Tokai University Tokyo \\ Hospital, Tokyo 15I-0053, Japan
}

Correspondence: Masakazu Ichinose Email ichinose@h-osaki.jp

\begin{abstract}
Purpose: Patients with chronic obstructive pulmonary disease (COPD) have decreased physical activity (PA) compared with healthy adults. As lower PA is associated with increased mortality, improving PA is an important objective for COPD management. This large-scale, multicenter, non-interventional, cross-sectional study examined the activity status of COPD patients in Japan and explored factors related to PA.

Patients and Methods: Outpatients aged $\geq 40$ years with confirmed COPD diagnosis and pulmonary function test data were enrolled. Primary study outcomes were measurement of daily steps (over 14 consecutive days, using an activity monitor), assessment of activity time by activity intensity (using metabolic equivalents [METs]), and evaluation of correlation between PA and patient characteristics. Secondary outcomes included further investigation of the influence of patient characteristics on PA.

Results: Data from 417 patients with Global Initiative for Chronic Obstructive Lung Disease (GOLD) stages I (29.5\%), II (43.9\%), III (23.5\%), and IV (3.1\%) were evaluated. Median (Q1, Q3) daily step count was $3440.8(1831.3,5709.3)$. Median $(\mathrm{Q} 1, \mathrm{Q} 3)$ durations of PA at $\geq 3$ (moderate-tovigorous) and $\geq 2$ METs (light-to-vigorous) were $18.7(6.5,41.3)$ and $186.9(126.9,259.2)$ minutes, respectively. For $>30 \%$ of patients, time spent in $\geq 3$ METs activity was $\leq 10$ minutes. Unemployment was significantly correlated with reduced activity time ( $\geq 3$ and $\geq 2$ METs) and step count. Severe GOLD stage was significantly correlated with reduced activity time ( $\geq 3$ and $\geq 2$ METs). High modified Medical Research Council (mMRC) dyspnea score was significantly correlated with reduced activity time ( $\geq 3$ METs) and step count. Patients tended to overestimate the time spent in activities requiring $\geq 2$ METs in their subjective reports compared with activity monitor measurements.
\end{abstract}

Conclusion: Reduced PA was observed in the Japanese COPD patients with the majority of them being GOLD stage I/II. Employment status, GOLD stage, and mMRC dyspnea score could help identify patients at risk of reduced PA.

Clinical Trial Registration: NCT03642613 (ClinicalTrials.gov); UMIN000032962 (UMIN-CTR, umin.ac.jp).

Keywords: COPD, physical activity, pulmonary function, activity monitor, step counts

\section{Introduction}

Chronic obstructive pulmonary disease (COPD) is a common respiratory disease, characterized by persistent symptoms and airflow limitation due to chronic inflammation often involving alveolar destruction. ${ }^{1,2}$ COPD generally develops after 
significant airway exposure to noxious substances, particularly tobacco smoke, and is a preventable and treatable disease; management includes smoking cessation and appropriate pharmacological therapy (eg, bronchodilators) to alleviate symptoms and slow disease progression. ${ }^{1}$ Globally, COPD is associated with high morbidity and is ranked as the fourth most common cause of death worldwide. ${ }^{3}$ In Japan, data collected in 2016 indicated that COPD was the eighth most common cause of mortality among males; ${ }^{4}$ moreover, according to a Japanese epidemiological observational survey conducted between December 2012 and August 2013, the prevalence of airflow limitation was $4.3 \%$ in adults aged $\geq 40$ years, rising to $6.1 \%$ in subjects with a history of smoking. ${ }^{5}$ The financial burden of treating COPD has also been reported to be particularly high in Japan compared with other countries. ${ }^{6}$

Physical activity (PA) is defined as any bodily movement produced by skeletal muscles that requires energy expenditure and is a complex behavior characterized by type, intensity, duration of PA, and patterns. ${ }^{7,8}$ It is commonly defined using metabolic equivalents (METs), which correlate the expenditure of energy during PA to a standard resting metabolic rate. ${ }^{9,10}$ Patients with COPD have been reported to have a decreased level of PA compared with healthy adults, even at an early stage of the disease, ${ }^{11,12}$ and reduced PA has been shown to be associated with increased risks of worsening of symptoms, exacerbation, and mortality. ${ }^{13-15}$ Guidelines issued by the Japanese Respiratory Society for the diagnosis and treatment of COPD include improvement in exercise capacity and daily PA as a treatment goal. ${ }^{16}$ Therefore, understanding of the key factors involved is needed to achieve effective interventions to improve PA. To date, the PA status of Japanese COPD patients in real-world clinical situations is largely unknown. A single-center study $(\mathrm{n}=43)$ reported reduced PA in COPD patients $(-23.1 \%$ at $\geq 2.0$ METs [light-to-vigorous intensity activities], and $-50.9 \%$ at $\geq 3.0$ METs [moderate-to-vigorous intensity activities], compared with healthy subjects). ${ }^{17}$

Studies have indicated that PA in COPD patients may be affected by multiple factors including exercise tolerance, self-efficacy, and motivation. ${ }^{8,18,19}$ In addition, sociodemographic and environmental factors have been reported to affect $\mathrm{PA},{ }^{8,11,20}$ and a correlation between pulmonary function and PA has also been suggested. ${ }^{21-23}$ Factors such as age and body mass index (BMI) were also reported to be correlated with PA. However, studies aiming to identify factors related to PA in COPD patients are limited in Japan, and no nationwide assessment has been reported to date. Thus, it remains unclear which factors are correlated with PA in Japanese COPD patients.

To clarify some of these issues, we conducted a largescale, multicenter, cross-sectional study to examine the PA status of COPD patients in Japan and to explore factors related to PA.

\section{Materials and Methods Study Design}

This was a multicenter, non-interventional, cross-sectional study conducted between 14 September 2018 and 2 January 2019 at 20 sites across Japan. Patients were enrolled in the study by a continuous central registration method to avoid selection bias. After enrollment, patients answered the questionnaires and started measurement of PAs within 4 weeks. PAs included step count, activity intensity (METs), activity time, and energy expenditure and were measured using a validated triaxial activity monitor (model HJA-750C, Omron Healthcare Co., Ltd., Kyoto, Japan). ${ }^{24}$ The activity monitor was calibrated and provided by the manufacturer so that no operation by the study investigators or patients was required. Investigators explained to patients how to use the activity monitor in accordance with the manufacturer's instructions. Patients wore the activity monitor for 14 consecutive days before returning it to each study site. As this was a noninterventional study, no treatments were mandated by the study protocol.

The study was performed in accordance with the ethical principles that have their origins in the Declaration of Helsinki, the International Conference on Harmonisation Good Clinical Practice guidelines, and all applicable national and international laws and regulations. The study protocol was approved by the ethics committee or the institutional review board of each study site, including the ethics review board of the Tohoku Medical and Pharmaceutical University Wakabayashi Hospital. All patients provided written informed consent before enrollment and study participation, and all patient data are protected in accordance with the Act on the Protection of Personal Information.

\section{Patients}

To be eligible for enrollment in the study, patients had to meet the following inclusion criteria: men and women over the age of 40 years with a diagnosis of COPD 
(according to the COPD guidelines published by the Japanese Respiratory Society) ${ }^{16}$ by a physician at the time of registration; patients with pulmonary function test data after bronchodilator administration; patients with data on diffusing capacity of the lung carbon monoxide $\left(\mathrm{DL}_{\mathrm{CO}}\right)$ value, or data on the presence or absence of emphysema by chest computed tomography (CT) examination; and outpatients who were able to respond to the questionnaire within 4 weeks after providing consent and could provide measurements for 14 consecutive days using an activity monitor.

Key exclusion criteria were patients who had participated in other clinical trials within the past 8 weeks; patients who were likely to fail to comply with study procedures, restrictions, and requirements as judged by an investigator; patients with exacerbation of COPD within the past 8 weeks; and patients requiring home oxygen therapy, although patients who used oxygen therapy only at night were permitted.

\section{Study Outcomes and Assessments}

The primary study outcomes were (i) daily steps, (ii) activity time measured by activity intensity (METs), and (iii) correlation between PA and patient characteristics.

Secondary study outcomes included an investigation of the influence of patient characteristics on PA. The evaluation of patient demographic and clinical characteristics included sex, age, BMI, smoking history, duration of COPD, comorbidities, medical history, COPD stage, prescription status of medications over the past year (including inhaled corticosteroids [ICS]), exacerbation over the past year, and presence/absence of an asthma component (medical history of asthma; presence/absence of a comorbidity/complication; date of diagnosis, if diagnosed with asthma; presence/absence of perennial allergic rhinitis; and latest test results [within the past 12 months] of peripheral eosinophil counts and fractional concentration of exhaled nitric oxide, total $\operatorname{IgE}$, and $\operatorname{IgE}$ specific to perennial inhaled antigens).

For pulmonary function, including forced expired volume in 1 second $\left(\mathrm{FEV}_{1}\right)$, forced vital capacity, and inspiratory capacity, the latest values prior to informed consent were collected. For $\mathrm{DL}_{\mathrm{CO}}$, emphysema, and body composition, the latest data within 1 year prior to informed consent were collected. Emphysema was evaluated using chest CT images and classified based on the proportion of emphysema in the lung field, as none $(0 \%)$, moderate $(<50 \%)$, and severe $(\geq 50 \%)$. Body composition (BMI, lean body mass, muscle mass, and fat free mass index) was assessed using a bioelectrical impedance analyzer (InBody, Cerritos, CA, USA).

The questionnaires used during the study included the modified Medical Research Council (mMRC) questionnaire (Japanese version) ${ }^{16}$ for evaluation of dyspnea, the COPD Assessment Test (CAT) ${ }^{25,26}$ for assessment of quality of life, and the COPD Status Survey sheet, which is a questionnaire designed for this study aiming to explore daily life and activity motivation (Supplementary Table 1). Items of the COPD Status Survey sheet included residential environment (housing), presence/absence of employment, daily activities (hobbies, activity time), socialization (frequency of outings, transportation method, enthusiasm), weather on the day of activity measurement, and the presence/absence of events requiring unusual levels of activity.

\section{Statistical Analyses}

One of the study objectives was to explore and identify factors related to $\mathrm{PA}$ in patients with COPD. Using a model previously published, ${ }^{27}$ and assuming that five factors as explanatory variables would be used in multiple regression analysis in this study, achievement of a moderate correlation at $80 \%$ power was calculated to require 419 patients. Considering the likely number of dropouts and patients from whom necessary data could not be obtained, the sample size for this study was determined to be 500 patients.

Based on previous studies using activity monitors, a measurement duration of at least 3 days was necessary to achieve sufficient reliability for estimation of habitual activity $^{28}$ and assessment of intraclass correlation coefficients. $^{29}$ Therefore, patients with activity monitor data of less than 3 days were excluded from the full analysis set (FAS). Further analysis was carried out in the activity monitor classification (AMC)-FAS population. The AMCFAS population included patients who had $\geq 3$ days of activity monitor data that fulfilled all of the following criteria: (i) data for $\geq 8$ hours per day; (ii) data obtained on fine or cloudy days (not rainy or snowy days); and (iii) data obtained on 'usual' days based on patient responses (ie, no unusual events occurred requiring abnormal activity levels). Daily step count (steps/day) was calculated as the mean of step counts of each day. The duration of PA was assessed as an average daily duration (minutes) of $\geq 2$ or $\geq 3$ METs. ${ }^{9,10}$

All data were summarized with appropriate descriptive statistics. No imputation was made for missing data. Due to 
the descriptive nature of this study, no adjustment for multiplicity was planned. Univariate correlations were made using Spearman's correlation coefficient and the strength of the correlation was interpreted based on the magnitude of the correlation coefficient as negligible $(\leq 0.3)$, weak $(>0.3$, $\leq 0.5)$, moderate $(>0.5, \leq 0.7)$, strong $(>0.7, \leq 0.9)$, and very strong $(>0.9){ }^{30}$ Adjusted means with $95 \%$ confidence intervals and p-values were summarized for each comparison. For activity time and step count, analysis based on a multiple regression model was performed in factors including demographic variables. Co-linearity between factors was measured using Cramer's V (Cramer's V absolute value $\geq 0.8$ indicates a high association), and variables with lower p-values were discarded. The remaining variables were introduced into the multiple regression analysis using the forward method with a threshold value of 0.15 . The regression coefficients and p-values were calculated according to a reference value with a regression coefficient of 0 . All statistical analyses were performed using SAS $^{\circledR}$ Enterprise Guide Analytics 7.1 (SAS Institute Inc., Cary, NC, USA).

\section{Results}

\section{Patients}

In total, 503 patients were enrolled into the study, of whom 417 were included in the AMC-FAS (Figure 1). In the
AMC-FAS, the majority of patients $(85.9 \%)$ were male; the mean age was 73.6 years; and the mean BMI was $22.4 \mathrm{~kg} / \mathrm{m}^{2}$ (Table 1). Most patients had a history of smoking (current, 12.0\%; former, 83.9\%). The mean duration of COPD was 6.2 years. The mean CAT score was 10.1 and the mean mMRC dyspnea score was 1.1 .

Overall, $369(88.7 \%)$ patients had emphysematous changes on CT scan (Table 2); of these, $68.9 \%$ had moderate emphysema and $20.0 \%$ had severe emphysema. The distribution of patients with Global Initiative for Chronic Obstructive Lung Disease (GOLD) stages I, II, III, and IV was $29.5 \%, 43.9 \%, 23.5 \%$, and 3.1\%, respectively. More than three-quarters of patients $(77.0 \%)$ had at least one comorbidity, of which the most common were hypertension (39.3\%) and asthma (31.4\%). Treatments for COPD are described in Supplementary Table 2.

Based on responses obtained from the COPD Status Survey, almost half of patients (191/417 [45.8\%]) lived in a detached house with stairs, 116/417 (27.8\%) lived in a detached house without stairs, and 45/417 (10.8\%) and $65 / 417(15.6 \%)$, respectively, lived in an apartment with or without stairs. We found that almost two-thirds of patients $(274 / 417$ [65.7\%]) were currently unemployed and that the majority of patients (350/417 [83.9\%]) lived with another person. A lack of participation in hobbies

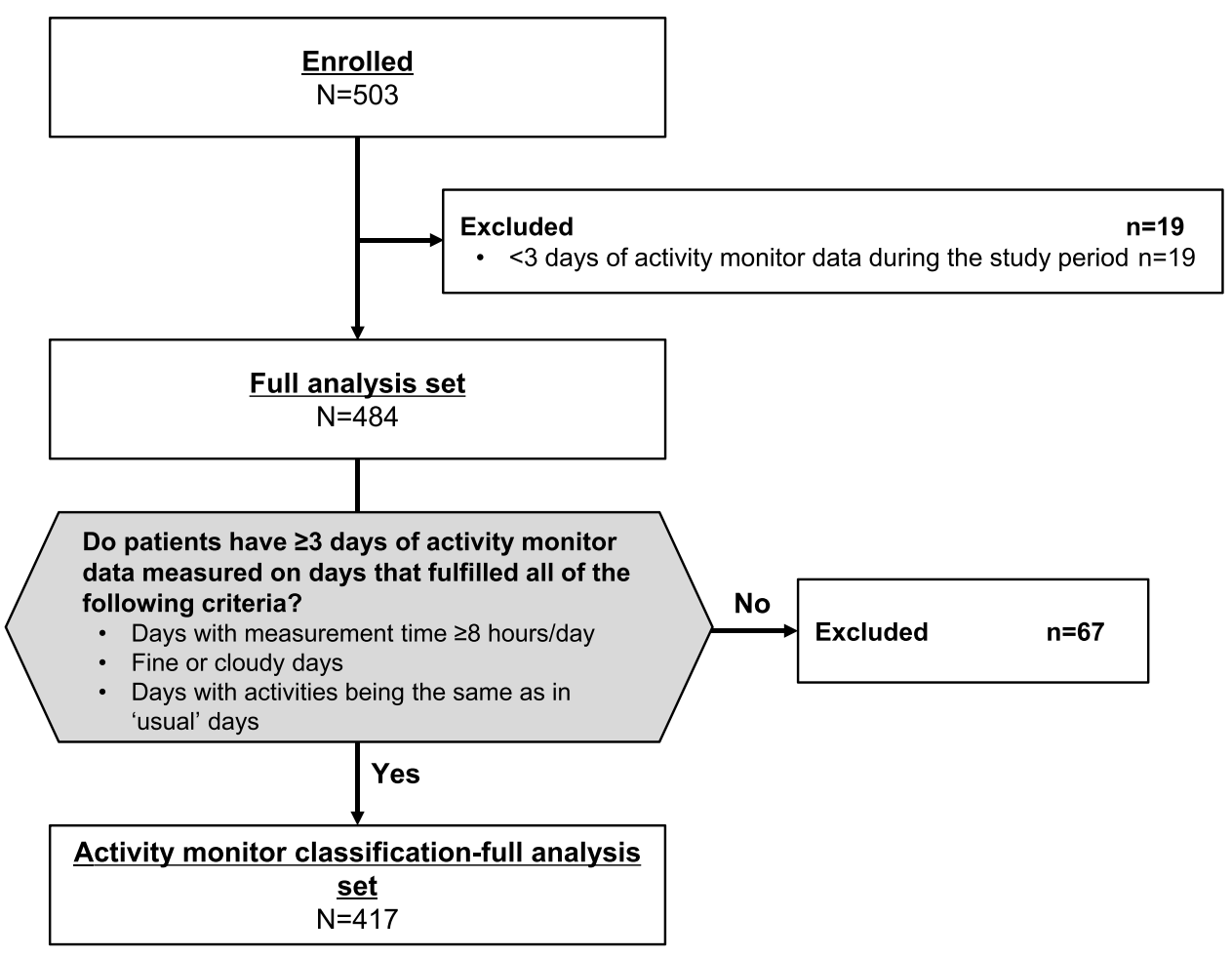

Figure I Patient disposition. 
Table I Patient Demographic Characteristics

\begin{tabular}{|l|l|l|}
\hline Characteristics & N & AMC-FAS Population \\
\hline Sex (male), $\mathrm{n}(\%)$ & 417 & $358(85.9)$ \\
Age (years) & 417 & $73.6(7.5)$ \\
BMI (kg/m $\left.{ }^{2}\right)$ & $4 I 7$ & $22.4(3.4)$ \\
\hline Smoking status, $\mathrm{n}(\%)$ & 417 & \\
$\quad$ Currently smoke & & $50(12.0)$ \\
Smoked in the past & & $350(83.9)$ \\
$\quad$ Never smoked & & $17(4.1)$ \\
\hline Pack years & 400 & $53.1(32.0)$ \\
Time since COPD onset (years) & $4 I 2$ & $6.2(5.2)$ \\
Body fat percentage (\%) & 120 & $26.9(6.9)$ \\
Lean body mass (kg) & 120 & $43.6(8.5)$ \\
Muscle mass (kg) & 120 & $41.0(8.2)$ \\
FFMl (kg/m $\left.{ }^{2}\right)$ & 120 & $16.2(2.0)$ \\
CAT score & $4 I 7$ & $10.1(6.7)$ \\
mMRC dyspnea score & 415 & $1.1(0.9)$ \\
\hline
\end{tabular}

Note: Data are shown as mean (SD) unless otherwise stated.

Abbreviations: AMC-FAS, activity monitor classification-full analysis set; BMI, body mass index; CAT, COPD Assessment Test; COPD, chronic obstructive pulmonary disease; FFMI, fat free mass index; mMRC, modified Medical Research Council; SD, standard deviation.

or community activities was reported by $136 / 416$ $(32.7 \%)$ patients. Of those patients who did participate, $55 / 416(13.2 \%)$ remained indoors, $106 / 416$ (25.5\%) went outdoors, and 119/416 (28.6\%) reported both indoor and outdoor activities. Mean (standard deviation) time per day of physical labor/vigorous sport and walking/ standing, which roughly corresponded to PA at $\geq 2$ METs, was 366.7 (221.8) minutes in total.

\section{Primary Outcome}

The median (Q1, Q3) and mean (standard deviation [SD]) daily step count in the AMC-FAS population were 3440.8 (1831.3, 5709.3) and 4064.4 (2984.4), respectively (Figure 2A). The median (Q1, Q3) and mean (SD) total duration of PA at $\geq 3$ METs were $18.7(6.5,41.3)$ minutes and 28.8 (29.7) minutes, respectively (Figure 2B). Notably, in more than $30 \%$ of patients, the time spent in PA at $\geq 3$ METs was $\leq 10$ minutes. The median (Q1, Q3) and mean (SD) total duration of PA at $\geq 2$ METs were 186.9 (126.9, 259.2) minutes and 201.2 (99.1) minutes, respectively (Figure 2C).

Pulmonary function, shortness of breath, and age were weakly correlated with PA at $\geq 3$ METs (Supplementary Table 3 ). The correlation between PA at $\geq 2$ METs and all items investigated in this study was negligible.

The median (Q1, Q3) total duration of PA at $\geq 2$ METs measured using an activity monitor (186.9 [126.9, 259.2]
Table 2 Patient Clinical/Laboratory Characteristics

\begin{tabular}{|c|c|c|}
\hline Characteristics & $\mathbf{N}$ & $\begin{array}{l}\text { AMC-FAS } \\
\text { Population }\end{array}$ \\
\hline $\begin{array}{l}\text { Post-bronchodilator FVC (L) } \\
\text { Post-bronchodilator FEV I (L) } \\
\text { Post-bronchodilator FEV,/FVC (\%) } \\
\text { FEV , (\% predicted) } \\
\text { Inspiratory capacity (L), mean (SD) } \\
\text { [median] }\end{array}$ & $\begin{array}{l}417 \\
417 \\
417 \\
417 \\
417\end{array}$ & $\begin{array}{l}3.13(0.88) \\
1.70(0.65) \\
54.1(12.7) \\
65.8(21.1) \\
2.17(0.58)[2.2]\end{array}$ \\
\hline $\begin{array}{l}\text { GOLD stage, n (\%) } \\
\text { I } \\
\text { II } \\
\text { III } \\
\text { IV }\end{array}$ & 417 & $\begin{array}{l}123(29.5) \\
183(43.9) \\
98(23.5) \\
13(3.1)\end{array}$ \\
\hline $\begin{array}{l}\text { Presence of emphysema by CT, n (\%) } \\
\text { No } \\
\text { Yes }\end{array}$ & 416 & $\begin{array}{l}47 \text { (I I.3) } \\
369(88.7)\end{array}$ \\
\hline $\begin{array}{l}\text { Evaluation of emphysema by } \mathrm{CT}, \mathrm{n}(\%) \\
\text { None }(0 \%) \\
\text { Moderate }(<50 \%) \\
\text { Severe }(\geq 50 \%)\end{array}$ & $4 I I$ & $\begin{array}{l}46(11.2) \\
283(68.9) \\
82(20.0)\end{array}$ \\
\hline $\begin{array}{l}\text { Pulmonary diffusing capacity disorder, } \\
\text { n (\%) } \\
\text { No } \\
\text { Yes }\end{array}$ & 414 & $\begin{array}{l}143(34.5) \\
27 \mid(65.5)\end{array}$ \\
\hline $\begin{array}{l}\text { Eosinophils ratio }(\%) \\
\text { Peripheral eosinophils count (cells } / \mu \mathrm{L}) \\
\text { FeNO measurement (ppb) }\end{array}$ & $\begin{array}{l}278 \\
278 \\
225\end{array}$ & $\begin{array}{l}3.6(2.4) \\
221.4(156.4) \\
25.7(20.3)\end{array}$ \\
\hline $\begin{array}{l}\text { At least one complication/comorbidity } \\
\text { Hypertension } \\
\text { Asthma } \\
\text { Diabetes } \\
\text { Ischemic heart disease } \\
\text { Gastroesophageal reflux disease } \\
\text { Osteoporosis } \\
\text { Heart failure } \\
\text { Depression/anxiety }\end{array}$ & 417 & $\begin{array}{l}321(77.0) \\
164(39.3) \\
131(31.4) \\
59(14.1) \\
40(9.6) \\
40(9.6) \\
15(3.6) \\
14(3.4) \\
13(3.1)\end{array}$ \\
\hline
\end{tabular}

Note: Data are shown as mean (SD) unless otherwise stated.

Abbreviations: AMC-FAS, activity monitor classification-full analysis set; CT, computed tomography; FeNO, fractional concentration of exhaled nitric oxide; $\mathrm{FEV}_{1}$, forced expired volume in I second; FVC, forced vital capacity; GOLD, Global Initiative for Chronic Obstructive Lung Disease; SD, standard deviation.

minutes) was lower than the median (Q1, Q3) duration of patient-reported light-to-moderate activities, which roughly corresponded to PA at $\geq 2$ METs (360.0 [180.0, 510.0] minutes). The relationship between the device-monitored total activity time in patients participating in PA at $\geq 2$ METs and patient-reported durations of walking/standing and physical labor/vigorous sport (activities deemed to be $\geq 2$ METs) is 

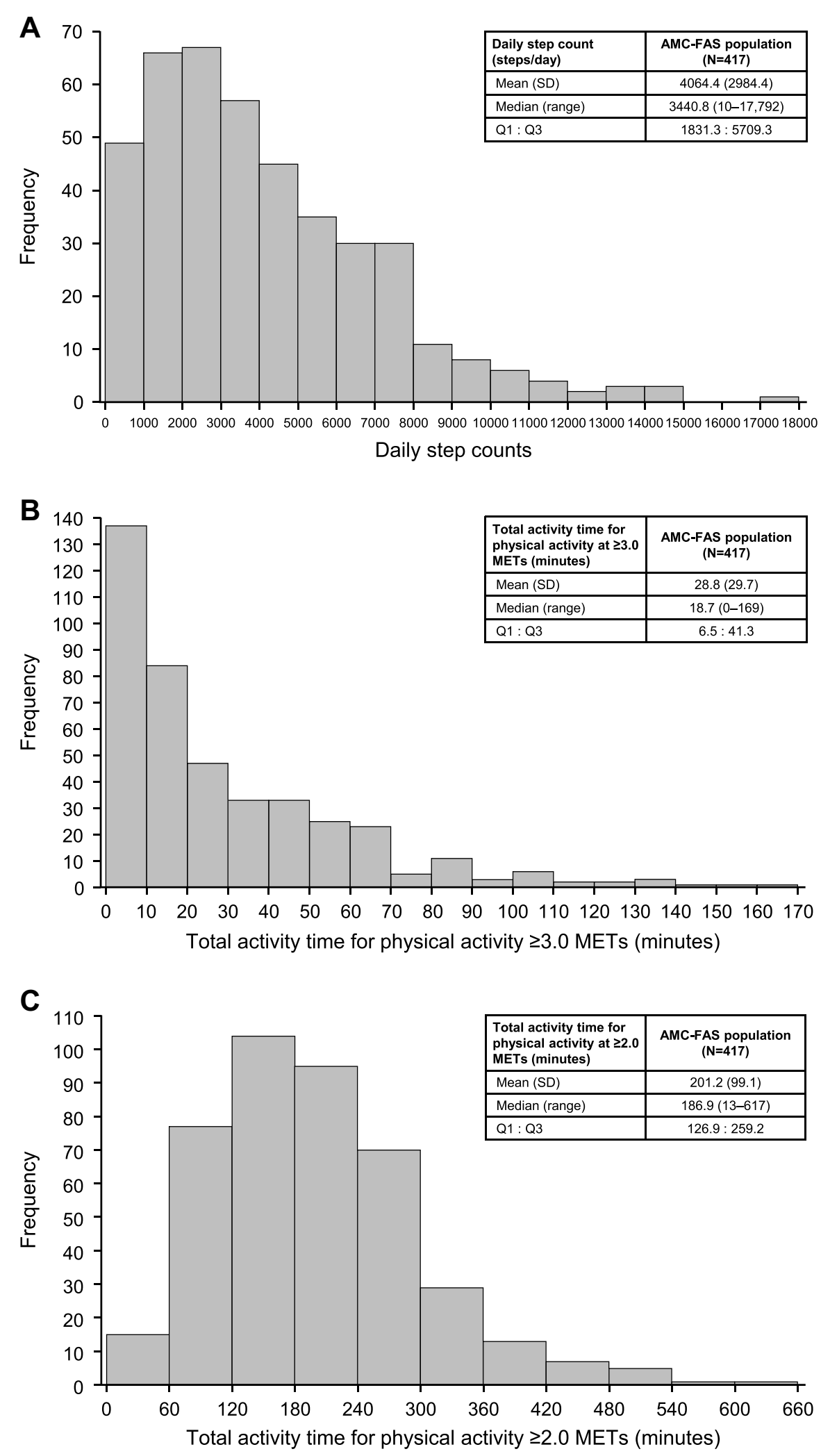

Figure 2 Daily activity. (A) The frequency of steps for the AMC-FAS population. (B) Activity time for physical activity at $\geq 3.0$ METs. (C) Activity time for physical activity at $\geq 2.0$ METs.

Abbreviations: AMC-FAS, activity monitor classification-full analysis set; MET, metabolic equivalent; Q, quartile; SD, standard deviation. 


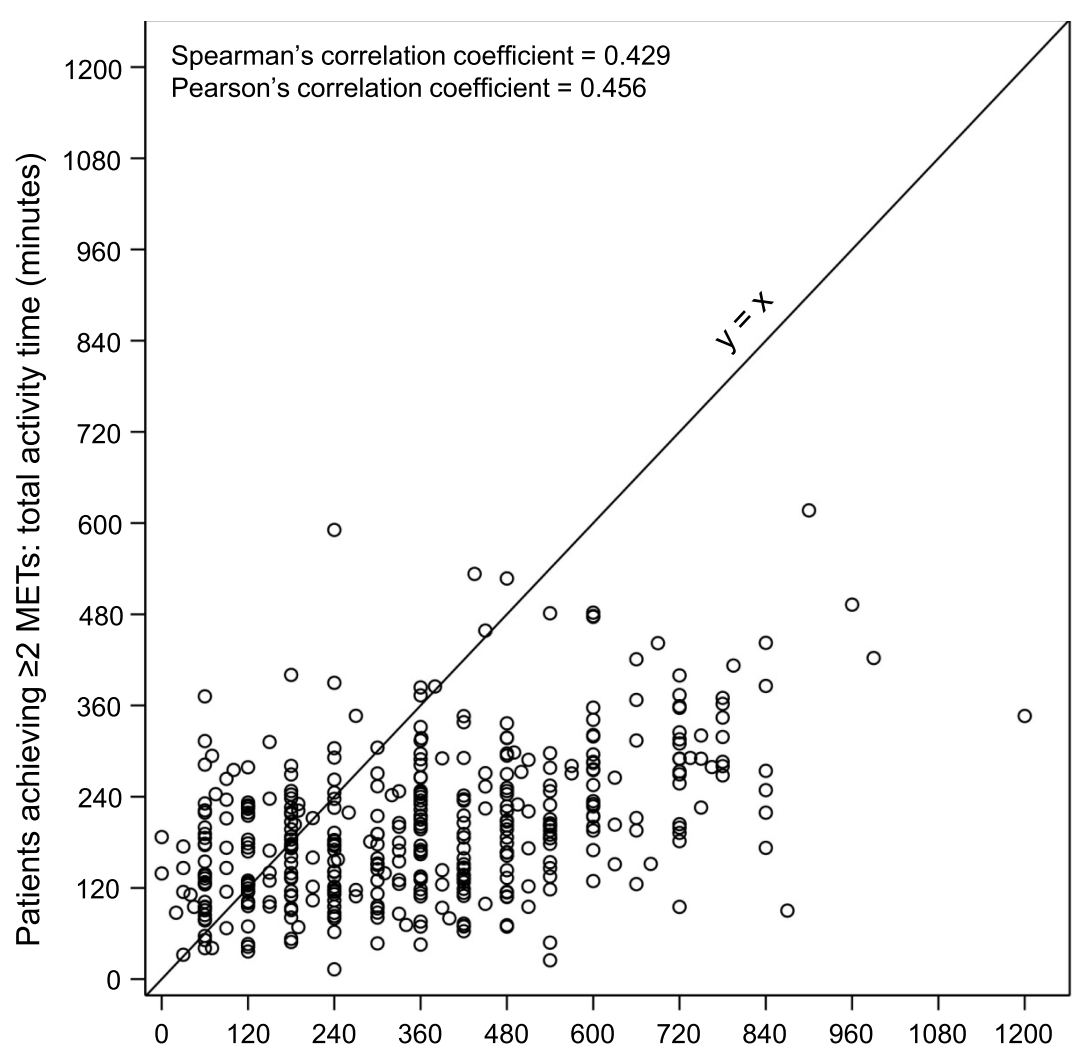

Patient-reported durations of activity corresponding to $\geq 2$ METs (minutes)

\begin{tabular}{|l|c|c|}
\hline & $\begin{array}{c}\text { Total activity time for physical } \\
\text { activity at } \mathbf{2} \mathbf{2} \mathbf{0} \text { METs (minutes) }\end{array}$ & $\begin{array}{c}\text { Total average time per day of } \\
\text { physical labor or vigorous sport } \\
\text { and walking or standing (minutes) }\end{array}$ \\
\hline $\mathrm{N}$ & 417 & 398 \\
\hline Mean (SD) & $201.2(99.1)$ & $366.7(221.8)$ \\
\hline Median (range) & $186.9(13-617)$ & $360.0(0-1200)$ \\
\hline Q1 : Q3 & $126.9: 259.2$ & $180.0: 510.0$ \\
\hline
\end{tabular}

Figure 3 Correlations between the total activity time in patients achieving $\geq 2$ METs and patient-reported durations of activities equivalent to $\geq 2$ METs.

Abbreviations: MET, metabolic equivalent; $\mathrm{Q}$, quartile; SD, standard deviation.

shown in Figure 3. As indicated, patients tended to overestimate the time spent in activities requiring $\geq 2$ METs in their subjective reports compared with the time measured by an activity monitor (366.7 vs 201.2 minutes).

\section{Influence of Patient Characteristics on PA}

The relationship between METs and patient characteristics was evaluated using univariate and multivariate analyses (Supplementary Table 4 and Table 3). While many factors were correlated with activities at $\geq 3.0$ METs in the univariate analysis, age $(\geq 74$ to $<79$ years, $\mathrm{p}=0.0060$; $\geq 79$ years, $\mathrm{p}<0.0001$ ), GOLD stage (stage III, $\mathrm{p}=0.0008$; stage IV, $\mathrm{p}=0.0019$ ), mMRC dyspnea score (score of $1, \mathrm{p}=0.0166$; score of $\geq 2, \mathrm{p}=0.0001$ ), and employment status (not employed, $\mathrm{p}<0.0001$ ) were found to be correlated in the multivariate analysis. Analysis results for activities at $\geq 2.0$ METs are shown in Supplementary Table 5 and Table 4. Sex, GOLD stage, employment status, and living with another person were found to be correlated in the multivariate analysis. Univariate and multivariate analysis results for step counts are shown in Supplementary Table 6 and Table 5. mMRC dyspnea score $\geq 2$ and lack of employment were found to be significantly correlated with number of steps (both $\mathrm{p}<0.0001$ ).

\section{Discussion}

To our knowledge, this is the first large-scale study to have revealed the actual PA status of Japanese patients with COPD and to have explored factors affecting PA. Our data demonstrate PA, which is one of the factors most likely to affect the 
Table 3 Multivariate Analysis of $\geq 3.0$ METs Activity Time

\begin{tabular}{|l|l|l|l|}
\hline Factors & Coefficient & $\begin{array}{l}\text { Standard } \\
\text { Error }\end{array}$ & p-value \\
\hline $\begin{array}{l}\text { Age (years) } \\
<69\end{array}$ & & & Reference \\
$\geq 69$ to $<74$ & -5.7832 & 3.747 I & 0.1235 \\
$\geq 74$ to $<79$ & -10.3509 & 3.7475 & 0.0060 \\
$\geq 79$ & -20.0063 & 3.8480 & $<0.000$ I \\
\hline GOLD stage & & & \\
I & & & Reference \\
II & -2.6361 & 3.1200 & 0.3987 \\
III & -12.3668 & 3.6648 & 0.0008 \\
IV & -24.5367 & 7.8574 & 0.0019 \\
\hline mMRC dyspnea score & & & \\
0 & & & Reference \\
I & -7.4877 & 3.1136 & 0.0166 \\
$\geq 2$ & -13.9673 & 3.6019 & 0.0001 \\
\hline Job status & & & \\
Employed & & & $<0.0001$ \\
Not employed & -13.2208 & 2.8632 & \\
\hline
\end{tabular}

Abbreviations: GOLD, Global Initiative for Chronic Obstructive Lung Disease; MET, metabolic equivalent; mMRC, modified Medical Research Council.

prognosis of COPD, ${ }^{13-15,31}$ in a broad population of COPD patients enrolled from across Japan. We found notable inconsistencies between the actual PA durations measured by the activity monitor and the activity times reported by patients themselves. In addition, regression analyses revealed factors

Table 4 Multivariate Analysis of $\geq 2.0$ METs Activity Time

\begin{tabular}{|c|c|c|c|}
\hline Factors & Coefficient & Standard Error & p-value \\
\hline \multicolumn{4}{|l|}{ Sex } \\
\hline Female & & & Reference \\
\hline Male & -41.2201 & 12.8688 & 0.0015 \\
\hline \multicolumn{4}{|l|}{ GOLD stage } \\
\hline I & & & Reference \\
\hline II & $-|8.758|$ & $10.398 \mid$ & 0.0720 \\
\hline III & -49.6694 & 12.0910 & $<0.0001$ \\
\hline IV & -127.5926 & 26.0385 & $<0.000$ I \\
\hline \multicolumn{4}{|l|}{ Job status } \\
\hline Employed & & & Reference \\
\hline Not employed & -66.3723 & 9.2198 & $<0.0001$ \\
\hline \multicolumn{4}{|l|}{ Live with anybody? } \\
\hline Yes & & & Reference \\
\hline No & -35.0297 & 12.2164 & 0.0044 \\
\hline
\end{tabular}

Abbreviations: COPD, chronic obstructive pulmonary disease; GOLD, Global Initiative for Chronic Obstructive Lung Disease; MET, metabolic equivalent.
Table 5 Multivariate Analysis of Step Counts

\begin{tabular}{|c|l|l|l|}
\hline Factors & Coefficient & Standard Error & p-value \\
\hline mMRC dyspnea score & & & \\
0 & & & $\begin{array}{l}\text { Reference } \\
0.4579 \\
\text { I }\end{array}$ \\
$\geq 2$ & -245.7503 & 330.7548 & $<0.000 \mathrm{I}$ \\
\hline Job status & -1779.8622 & 365.0076 & \\
Employed & & & Reference \\
Not employed & -1332.3057 & 295.5853 & $<0.000 \mathrm{I}$ \\
\hline
\end{tabular}

Abbreviation: mMRC, modified Medical Research Council.

that are associated with step counts and with $\geq 3$ METs and $\geq 2$ METs activities, which we assessed for PA in this study.

The step counts measured in our study were lower than those previously reported for healthy elderly individuals in Japan and those reported for COPD patients in other countries. Furthermore, although the majority of our study population had mild COPD, decreased PA was reported. According to statistics collected by the Ministry of Health, Labour and Welfare in Japan, the mean daily steps reported by male adults aged $\geq 65$ years in Japan in 2015 was 5919 steps. ${ }^{32}$ In our study, the mean daily step count by COPD patients was 4064 steps (median 3440.8 steps), which corresponds to around $70 \%$ of the normal elderly population. Although there are no direct comparisons between step counts from Japanese and non-Japanese COPD patients in the published literature, our large-scale study indicated that the step count of COPD patients in Japan was lower than those reported in other countries (Germany [ $\mathrm{n}=170]$, mean 5882 steps; ${ }^{33}$ Switzerland $[\mathrm{n}=70]$, mean 5272 steps; $^{34}$ United States $[\mathrm{n}=171], 5203$ steps; ${ }^{35}$ Netherlands and United Kingdom [ $\mathrm{n}=127$ ], mean 4725 steps). ${ }^{36}$ These differing results may be explained by differences in patient characteristics, including sex, age, and lung function. Of note, $70 \%$ of patients in our study were classified as GOLD stage I or II; thus, our results also indicate that PA was impaired even in patients with a slight decrease in pulmonary function.

There is no evidence-based, clear-cut threshold to judge PA impairment in Japan. According to the Japanese Ministry of Health, Labour and Welfare, the target step count for subjects aged $\geq 65$ years is 7000 steps/day in men and 6000 steps/day in women, ${ }^{37}$ the target PA is 23 METs $\cdot$ hour/day (activities at $\geq 3$ METs) in subjects aged 18-64 years, and 10 METs hour/day (regardless of intensity of PA) in subjects aged $\geq 65$ years, which corresponds to roughly 40 minutes of 
activity. ${ }^{38}$ While these target values only apply to the general population, they may be useful as reference values in clinical practice for the management of patients with COPD.

It has been suggested that activity levels self-reported by COPD patients are not always accurate; ${ }^{39}$ thus, the evaluation of PA should not rely only on subjective measurements reported by patients. In our study there were inconsistencies between the actual PA durations measured by the activity monitor (median 186.9 minutes of PA at $\geq 2$ METs) and the activity times reported by patients themselves (median 360.0 minutes of light-to-moderate activities), indicating that the duration of light-to-moderate intensity activities tends to be overestimated by patients.

In this study, employment status, COPD disease grade, and mMRC dyspnea score were found to be associated with more than one measure of physical activity. Employment status affected step counts, duration of PA at $\geq 2$ METs, and duration of PA at $\geq 3$ METs; COPD disease grade affected duration of $\mathrm{PA}$ at $\geq 2$ METs and duration of PA at $\geq 3 \mathrm{METs}$; and $\mathrm{mMRC}$ dyspnea score affected step counts and duration of PA at $\geq 3$ METs. Our findings revealed that unemployment has an influence on PA as measured by step counts and duration of PA at $\geq 2$ METs and $\geq 3$ METs. Thus, healthcare professionals must take this factor into account when assessing PA, especially in patients around the age of retirement, emphasizing the importance of maintaining activities of daily life to the same level as that during employment. This patient group should also be encouraged to seek the support of friends and family to improve their PA. The implementation of urban walking circuits, through local government initiatives, has been shown to improve the level of PA among COPD patients ${ }^{40}$ and may be another useful strategy to encourage PA among retirees. Previous studies evaluating the impact of employment status on PA have been scarce. Because employment situation is a factor greatly influenced by the country, region, and environment, further research on the effects of these social factors on PA is required in the future.

In the present study, COPD disease grade is shown to be a factor influencing the duration of PA at $\geq 2$ METs and $\geq 3$ METs. A previous study reported an association between the COPD disease grade and both the duration of PA at $\geq 3$ METs and step counts. ${ }^{20}$ According to a Japanese study, the duration of PA at $\geq 2$ METs and $\geq 3$ METs was significantly correlated with $\mathrm{FEV}_{1}$ and forced vital capacity. ${ }^{17}$ However, current findings add to the evidence base by showing an association between the COPD disease grade and the duration of PA at $\geq 2$ METs. Our result indicates that evaluating airflow limitation by spirometry in daily practice could identify patients who are at risk of reduced PA among COPD patients. We also found an association between mMRC dyspnea score and both step counts and the duration of PA at $\geq 3$ METs, similar to findings reported in previous studies. $^{20,41}$ It has been shown that shortness of breath is particularly highly correlated with $\mathrm{PA}$ at $\geq 3$ METs. ${ }^{42}$ Assessments of mMRC are clinically important not only for understanding the severity of dyspnea but also for identifying patients who are at risk of reduced PA. The purpose of this study was to identify factors that affect the number of steps taken and the duration of PA at $\geq 2$ METs and $\geq 3$ METs. In multivariate analysis, age was not a significant factor affecting the number of steps and the duration of PA at $\geq 2$ METs, while it was a significant factor for the duration of PA at $\geq 3$ METs.

The results of our study have important implications for clinical practice. Although PA is one of the most important factors for COPD prognosis, it is difficult to evaluate in routine clinical practice. We confirm that subjective measurements of PA by patients are not accurate in assessing the level of PA; however, unemployment, severe airflow limitation, and shortness of breath during physical exertion are shown to be risk factors for reduced PA. Therefore, it is recommended that healthcare professionals routinely ascertain the employment status, assess the severity of airflow limitation by spirometry, and assess dyspnea on exertion using the mMRC questionnaire, in order to identify patients who are at risk of reduced PA. As currently available pharmacological therapies, such as a combination of bronchodilators and inhaled corticosteroids, have been proven to improve dyspnea ${ }^{43}$ and lung function, ${ }^{44}$ it is quite possible that active intervention may improve PA in COPD patients.

Our study has some limitations, which must be considered. This was a cross-sectional study in which it is difficult to establish whether a factor is a determinant of PA or an outcome resulting from different PA status. Since only outpatients who were able to measure PA using activity monitors for 14 consecutive days were included, the results cannot be extrapolated directly to patients under different conditions, such as primary care patients who make irregular visits, or inpatients. We also cannot rule out the effects of selection bias, although we made efforts to minimize this possibility via the 
continuous registration study design. Our study is also limited by the cohort effect. Japanese COPD patients are characterized by older age and higher proportion of males than Western COPD patients. ${ }^{45}$ Therefore, our findings could not be extrapolated to the non-Japanese population. Finally, the plan to account for weather by excluding data obtained during specific conditions may also be viewed as a limitation; as exacerbations are a factor of the COPD process, excluding exacerbating conditions may have resulted in falsely elevated PA.

\section{Conclusion}

The data from our study have enabled us to elucidate the real-world status of PA in COPD patients in Japan. Patients tend to overestimate their self-reported activity times compared with the durations of PA recorded using an activity monitor. However, evaluating employment status, COPD disease grade, and mMRC dyspnea score in daily practice could help identify patients who are at risk of reduced PA.

\section{Abbreviations}

AMC-FAS, activity monitor classification-full analysis set; BMI, body mass index; CAT, COPD Assessment Test; COPD, chronic obstructive pulmonary disease; CT, computed tomography; FAS, full analysis set; ICS, inhaled corticosteroids; $\mathrm{FEV}_{1}$, included forced expired volume in 1 second; GOLD, Global Initiative for Chronic Obstructive Lung Disease; MET, metabolic equivalent; mMRC, modified Medical Research Council; PA, physical activity.

\section{Data Sharing Statement}

Data underlying the findings described in this manuscript may be obtained in accordance with AstraZeneca's data sharing policy described at http://astrazenecagrouptrials. pharmacm.com/ST/Submission/Disclosure. The corresponding author had full access to all the data in the study and had final responsibility for the decision to submit for publication.

\section{Acknowledgments}

The authors thank Sally-Anne Mitchell, PhD, of Edanz Evidence Generation for providing medical writing support, which was funded by AstraZeneca K.K., Osaka, Japan through EMC K.K. in accordance with Good Publication Practice guidelines (http://www.ismpp.org/gpp3).

\section{Author Contributions}

All authors made substantial contributions to conception and design, acquisition of data, or analysis and interpretation of data; took part in drafting the article or revising it critically for important intellectual content; agreed to submit to the current journal; gave final approval of the version to be published; and agree to be accountable for all aspects of the work.

\section{Funding}

This study and its publication were funded by AstraZeneca K.K., Osaka, Japan. The funding source was involved in the study design, data collection, analysis and interpretation, and review of the manuscript.

\section{Disclosure}

Masakazu Ichinose has received honoraria for speaking from AstraZeneca, GSK, and Nippon Boehringer Ingelheim. Yoshiaki Minakata has received personal fees from AstraZeneca K.K. and Nippon Boehringer Ingelheim outside the submitted work. Takashi Motegi has received personal fees from AstraZeneca K.K. for the submitted work, and personal fees from Nippon Boehringer Ingelheim outside the submitted work. Ichiro Kuwahira has received honoraria for speaking from AstraZeneca, GSK, Nippon Boehringer Ingelheim, and Meiji Seika Pharma. Munehiro Seki, Satoko Sugaya, and Nobuya Hayashi are employees of AstraZeneca K.K. The authors report no other conflicts of interest in this work.

\section{References}

1. Global Initiative for Chronic Obstructive Lung Disease (GOLD). Global strategy for the diagnosis, management, and prevention of chronic obstructive pulmonary disease (2019 report); 2019. Available from: https://goldcopd.org/wp-content/uploads/2018/11/GOLD2019-v1.7-FINAL-14Nov2018-WMS.pdf. Accessed November 25, 2020.

2. Lowe KE, Regan EA, Anzueto A, et al. COPDGene ${ }^{(\mathrm{R})}$ 2019: redefining the diagnosis of chronic obstructive pulmonary disease. Chronic Obstr Pulm Dis. 2019;6:384-399. doi:10.15326/jcopdf.6.5.2019.0149

3. Lozano R, Naghavi M, Foreman K, et al. Global and regional mortality from 235 causes of death for 20 age groups in 1990 and 2010: a systematic analysis for the Global Burden of Disease Study 2010. Lancet. 2012;380:2095-2128. doi:10.1016/S0140-6736(12)61728-0

4. Japan Ministry of Health, Labour and Welfare. Health statistics; 2016. Available from: http://www.mhlw.go.jp/toukei/itiran/. Accessed November 25, 2020.

5. Omori H, Kaise T, Suzuki T, Hagan G. Prevalence of airflow limitation in subjects undergoing comprehensive health examination in Japan: survey of chronic obstructive pulmonary disease patients epidemiology in Japan. Int J Chron Obstruct Pulmon Dis. 2016;11:873-880. doi:10.2147/COPD.S99935 
6. Woo L, Smith HE, Sullivan SD. The economic burden of chronic obstructive pulmonary disease in the Asia-Pacific region: a systematic review. Value Health Reg Issues. 2019;18:121-131. doi:10.1016/j. vhri.2019.02.002

7. Caspersen CJ, Powell KE, Christenson GM. Physical activity, exercise, and physical fitness: definitions and distinctions for health-related research. Public Health Rep. 1985;100:126-131.

8. Watz H, Pitta F, Rochester CL, et al. An official European Respiratory Society statement on physical activity in COPD. Eur Respir J. 2014;44(6):1521-1537. doi:10.1183/09031936.00046814

9. Ainsworth BE, Haskell WL, Herrmann SD, et al. 2011 compendium of physical activities: a second update of codes and MET values. Med Sci Sports Exerc. 2011;43:1575-1581. doi:10.1249/MSS.0b $013 \mathrm{e} 31821$ ece 12

10. Ainsworth BE, Haskell WL, Whitt MC, et al. Compendium of physical activities: an update of activity codes and MET intensities. Med Sci Sports Exerc. 2000;32:S498-504. doi:10.1097/00005768200009001-00009

11. Pitta F, Troosters T, Spruit MA, Probst VS, Decramer M, Gosselink R. Characteristics of physical activities in daily life in chronic obstructive pulmonary disease. Am J Respir Crit Care Med. 2005;171:972-977. doi:10.1164/rccm.200407-855OC

12. Vorrink SN, Kort HS, Troosters T, Lammers JW. Level of daily physical activity in individuals with COPD compared with healthy controls. Respir Res. 2011;12:33. doi:10.1186/1465-9921-12-33

13. Gimeno-Santos E, Frei A, Steurer-Stey C, et al. Determinants and outcomes of physical activity in patients with COPD: a systematic review. Thorax. 2014;69:731-739. doi:10.1136/thoraxjnl-2013-204763

14. Vaes AW, Garcia-Aymerich J, Marott JL, et al. Changes in physical activity and all-cause mortality in COPD. Eur Respir J 2014;44:1199-1209. doi:10.1183/09031936.00023214

15. Waschki B, Kirsten A, Holz O, et al. Physical activity is the strongest predictor of all-cause mortality in patients with COPD: a prospective cohort study. Chest. 2011;140:331-342. doi:10.1378/chest.10-2521

16. The Japanese Respiratory Society. Guidelines for Diagnosis and Treatment of COPD (Chronic Obstructive Pulmonary Disease). 5th edition. Tokyo: Medical Review Co., Ltd; 2018.

17. Minakata Y, Sugino A, Kanda M, et al. Reduced level of physical activity in Japanese patients with chronic obstructive pulmonary disease. Respir Investig. 2014;52:41-48. doi:10.1016/j.resinv.2013.06.002

18. Bauman AE, Reis RS, Sallis JF, et al. Correlates of physical activity: why are some people physically active and others not? Lancet 2012;380:258-271. doi:10.1016/S0140-6736(12)60735-1

19. Wshah A, Selzler AM, Hill K, Brooks D, Goldstein R. Determinants of sedentary behaviour in individuals with COPD: a qualitative exploration guided by the theoretical domains framework. COPD. 2020;17:65-73. doi:10.1080/15412555.2019.1708883

20. Watz H, Waschki B, Meyer T, Magnussen H. Physical activity in patients with COPD. Eur Respir J. 2009;33:262-272. doi:10.1183/ 09031936.00024608

21. Paneroni M, Ambrosino N, Simonelli C, Bertacchini L, Venturelli M, Vitacca M. Physical activity in patients with chronic obstructive pulmonary disease on long-term oxygen therapy: a cross-sectional study. Int J Chron Obstruct Pulmon Dis. 2019;14:2815-2823. doi:10.2147/COPD.S228465

22. Waschki B, Kirsten AM, Holz O, et al. Disease progression and changes in physical activity in patients with chronic obstructive pulmonary disease. Am J Respir Crit Care Med. 2015;192:295-306. doi:10.1164/rccm.201501-0081OC

23. Yu T, Frei A, Ter Riet G, Puhan MA. Determinants of physical activity in patients with chronic obstructive pulmonary disease: a 5-year prospective follow-up study. Respiration. 2016;92:72-79. doi:10.1159/000447975

24. Miyamoto S, Minakata Y, Azuma Y, et al. Verification of a motion sensor for evaluating physical activity in COPD patients. Can Respir J. 2018;2018:8343705. doi:10.1155/2018/8343705
25. GOLD Japan Committee. The Japanese COPD Assessment Test, revised; 2012. Available from: http://www.gold-jac.jp/support_con tents/cat.html. Accessed February 23, 2012

26. Jones PW, Harding G, Berry P, Wiklund I, Chen WH, Kline Leidy N. Development and first validation of the COPD Assessment Test. Eur Respir J. 2009;34:648-654. doi:10.1183/09031936.00102509

27. Maxwell SE. Sample size and multiple regression analysis. Psychol Methods. 2000;5:434-458. doi:10.1037/1082-989X.5.4.434

28. Trost SG, McIver KL, Pate RR. Conducting accelerometer-based activity assessments in field-based research. Med Sci Sports Exerc. 2005;37:S531-543. doi:10.1249/01.mss.0000185657.86065.98

29. Sugino A, Minakata Y, Kanda M, et al. Validation of a compact motion sensor for the measurement of physical activity in patients with chronic obstructive pulmonary disease. Respiration. 2012;83:300-307. doi:10.1159/000330046

30. Hinkle DE, Wiersma W, Jurs SG. Applied Statistics for the Behavioral Sciences. 5th edition. Boston, MA: Houghton Mifflin Harcourt; 2003.

31. Rabinovich RA. Physical activity in COPD. Significance, prognosis, measurement and therapeutic interventions. Arch Bronconeumol. 2018;54:449-450. doi:10.1016/j.arbres.2018.01.011

32. Japan Ministry of Health, Labour and Welfare. National health and nutrition survey 2015. Table 59: Average value and standard deviation of the number of steps-By age group, average value, standard deviation-Total number, male, female, 20 years old or older. [In Japanese]; 2015. Available from: https://www.e-stat.go.jp/stat-search/file-download?statInfId= 000031556286\&fileKind $=0$. Accessed November 25, 2020.

33. Watz H, Waschki B, Boehme C, Claussen M, Meyer T, Magnussen H. Extrapulmonary effects of chronic obstructive pulmonary disease on physical activity: a cross-sectional study. Am J Respir Crit Care Med. 2008;177:743-751. doi:10.1164/rccm.200707-1011OC

34. van Gestel AJ, Clarenbach CF, Stowhas AC, et al. Predicting daily physical activity in patients with chronic obstructive pulmonary disease. PLoS One. 2012;7:e48081. doi:10.1371/journal.pone.0048081

35. Moy ML, Teylan M, Weston NA, Gagnon DR, Danilack VA, Garshick E. Daily step count is associated with plasma C-reactive protein and IL-6 in a US cohort with COPD. Chest. 2014;145:542-550. doi:10.1378/chest.13-1052

36. Waschki B, Spruit MA, Watz H, et al. Physical activity monitoring in COPD: compliance and associations with clinical characteristics in a multicenter study. Respir Med. 2012;106:522-530. doi:10.1016/j. rmed.2011.10.022

37. Ministry of Health, Labour and Welfare, Kenko Nippon, 21. Targets for improving lifestyle and social environment in relation to nutrition/ eating habits, physical activity/exercise, rest, drinking habits, smoking habits, and oral health; 2015. Available from: https://www. nibiohn.go.jp/eiken/kenkounippon21/kenkounippon21/mokuhyou05. html. Accessed October 22, 2020.

38. Ministry of Health, Labour and Welfare. Physical activity standards for health promotion; 2013. Available from: https:/www.mhlw.go.jp/ stf/houdou/2r9852000002xple-att/2r9852000002xpqt.pdf. Accessed October 22, 2020.

39. Pitta F, Troosters T, Probst VS, Spruit MA, Decramer M, Gosselink R. Quantifying physical activity in daily life with questionnaires and motion sensors in COPD. Eur Respir J. 2006;27:1040-1055. doi:10.1183/09031936.06.00064105

40. Pleguezuelos E, Pérez ME, Guirao L, et al. Improving physical activity in patients with COPD with urban walking circuits. Respir Med. 2013;107:1948-1956. doi:10.1016/j.rmed.2013.07.008

41. Hayata A, Minakata Y, Matsunaga K, Nakanishi M, Yamamoto N. Differences in physical activity according to $\mathrm{mMRC}$ grade in patients with COPD. Int J Chron Obstruct Pulmon Dis. 2016;11:2203-2208. doi:10.2147/COPD.S109694

42. Nakanishi M, Minakata Y, Tanaka R, et al. Simple standard equation for daily step count in Japanese patients with chronic obstructive pulmonary disease. Int $J$ Chron Obstruct Pulmon Dis. 2019;14:1967-1977. doi:10.2147/COPD.S218705 
43. Rabe KF, Martinez FJ, Ferguson GT, et al. Triple inhaled therapy at two glucocorticoid doses in moderate-to-very-severe COPD. $N$ Engl J Med. 2020;383:35-48. doi:10.1056/NEJMoa1916046

44. Ferguson GT, Rabe KF, Martinez FJ, et al. Triple therapy with budesonide/glycopyrrolate/formoterol fumarate with co-suspension delivery technology versus dual therapies in chronic obstructive pulmonary disease (KRONOS): a double-blind, parallel-group, multicentre, Phase 3 randomised controlled trial. Lancet Respir Med. 2018;6:747-758. doi:10.1016/S2213-2600(18)30327-8
45. Ishii T, Nishimura M, Akimoto A, James MH, Jones $P$. Understanding low COPD exacerbation rates in Japan: a review and comparison with other countries. Int J Chron Obstruct Pulmon Dis. 2018;13:3459-3471. doi:10.2147/COPD.S165187

\section{Publish your work in this journal}

The International Journal of COPD is an international, peer-reviewed journal of therapeutics and pharmacology focusing on concise rapid reporting of clinical studies and reviews in COPD. Special focus is given to the pathophysiological processes underlying the disease, intervention programs, patient focused education, and self management protocols. This journal is indexed on PubMed Central, MedLine and CAS. The manuscript management system is completely online and includes a very quick and fair peer-review system, which is all easy to use. Visit http://www.dovepress.com/testimonials.php to read real quotes from published authors. 